\title{
The Incidence and Effect of Insect Bites on Servicemen in Belize
}

\author{
Dr N R H Burgess \\ MOD Adviser in Entomology \\ Royal Army Medical College
}

\section{SSgt I R J Crowe}

RAMC

\author{
Force Environmental Health Adviser \\ Airport Camp, Belize
}

SUMMARY: In the climate and terrain of Belize the incidence of insect bites and the risk of secondary infection are considerable. This is demonstrated by the large number of medical first attendances, attributed to infected bites, at Medical Centres in four Army locations, Airport Camp, Holdfast, Rideau and Salamanca. A breakdown of these figures, taken from the Monthly Minor Morbidity Return (AF W3181) and treatment books, shows that for three months (November and December 1981 and January 1982), 17\% of the total of 1825 first attendances were due to the effects of insect bites.

\section{Introduction}

Belize lies on the east coast of Central America between Mexico and Honduras and is bounded to the west by Guatemala. Its total area including the offshore islands (cayes) is just under 9,000 square miles, and the country measures a maximum of about 175 miles N-S and 70 miles E-W, thus being about the size of Wales.

A low coastal plain, covered mainly in mangrove swamps, runs N-S. The interior of the northern third of the country is hilly, up to $1000 \mathrm{ft}$ with areas of low tableland. To the south of this is the E-W valley of the Belize River, providing the main line of communication between Belize City on the coast, Belmopan, the capital, and eastern Guatemala. The central third of the country is made up of the limestone massif of the Maya and Cockscomb Mountains and Mountain Pine Ridge, rising in places to nearly $4,000 \mathrm{ft}$ and running NE to SW. The southern third of the country between the mountains in the extreme $W$ and the coast consists of a low lying forested area cut by a number of slow-moving rivers. The coastal waters are shallow for about 20 miles to the east, dotted with small islands and bounded by a coral reef second only in size to the Australian Great Barrier Reef. The climate is sub-tropical, damp and warm, and tempered by sea breezes along the coast. The temperature averages $75-80^{\circ} \mathrm{F}$ throughout the year. Annual rainfall ranges from 55 inches in the north to 175 inches in the south. More rain falls between June and January when it may be frequent and intense with as much as 8-10 inches in 24 hours and $100 \%$ relative humidity. In the drier months of February to May, both temperature and humidity are slightly lower. Hurricanes may occur in the summer month

The population of the country is nearly $150,00 \%$ increasing by about $4 \%$ annually. The main raciaj groups are Creoles who make up $50 \%$ of the popts lation (for example, mulattos of mixed Europeag and negro descent, and mestizos, of mixed Spanisho Portuguese and Amerindian descent), 10\% Caribs (native West Indian descent), $25 \%$ Amerindians (bot $\overrightarrow{0}$ Mayan and Ketchi), and 10\% Europeans.

\section{Insect Problems}

The incidence of bloodsucking flies in Belize is high. Probably the most common is the very small midge Culicoides known locally as a 'sand fiy' (Fig. ণ্ 1), no more than $2 \mathrm{~mm}$ in length but with a most irritating bite. Culicoides is found in most parts of $\overline{0}$ the country, breeding in wet decomposing organic

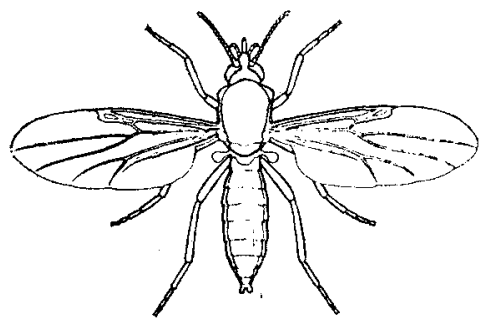

Adult female

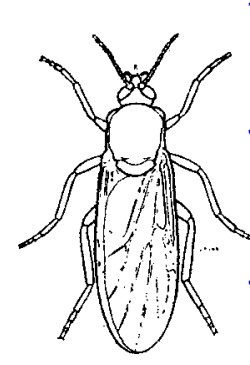

Adult-resting position

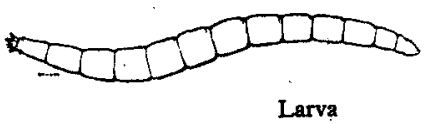

Fig. 1 Biting midge, Culicoides 
matter in such diverse environments as inland marshes, mangrove swamps and seaweed gathered on beaches. The midge bites mainly during the hours of daylight or into the evening.

In the forest areas, especially near rivers and streams the biting black fly Simulium (Fig. 2) is common and bites savagely during the day but not at night, prodding the skin with its short mouthparts until a small pool of blood is formed from which it feeds. This results in a tiny black scab at the site of attack. The fly is known locally as the 'Botlass fly', a name derived from the shape of its abdomen which resembles in miniature the bottle of a local brand of beer, hence 'bottle-arsed'.
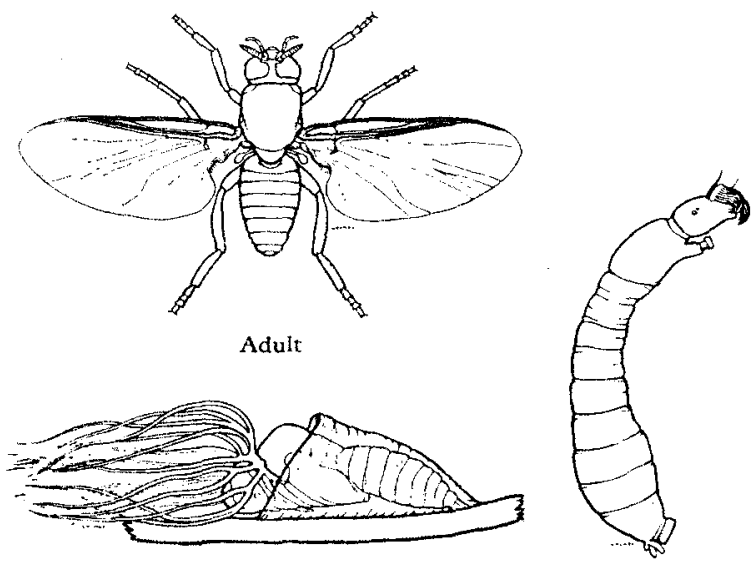

Pupa

Fig. 2 Black-fly, Simulium

In certain parts of the country the true sandfiy Phlebotomus (Fig 3) is locally common, though it is rarely found in camp areas. It will bite at dusk and dawn and throughout the night, and may also attack during the day in places such as caves or dark jungle. Its bite is sharp and irritating.
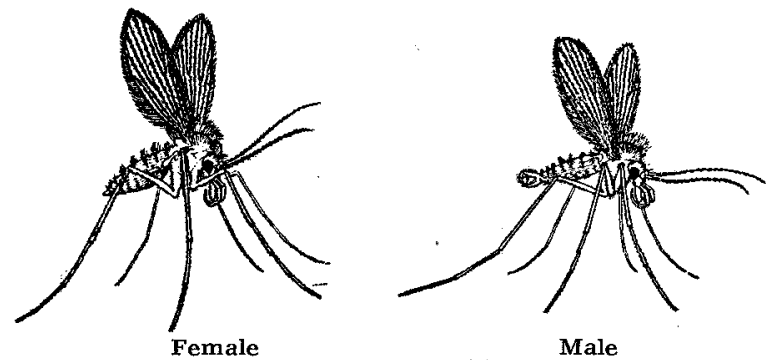

Fig. 3 Sandfy, Phlebotomus

Some 40 species of mosquitoes (Fig 4) are found throughout Belize. Most will typically bite at night, but a few will also feed during the hours of daylight.
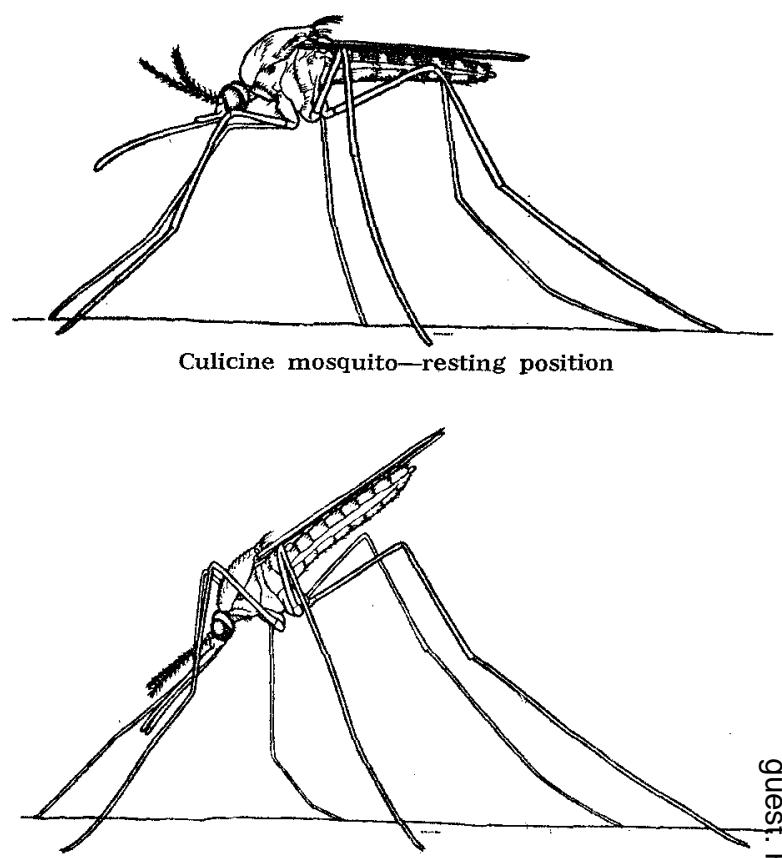

Anopheline mosquito-resting position

Fig. 4 Culicine and Anopheline mosquitoes

Several species of Chrysops (Fig 5) inflict painfuf bites with their scalpel-like mouthparts, giving the $\overrightarrow{0}$ insect its local name of 'doctor fly'. Infestation by the larval stages of the bot-fly Dermatobia hominis, (Fig 6) known locally as the 'beef worm', is a comeo mon cause of specific myiasis in Servicemen. Attack by several species of hard tick (Fig 7) is likely in infested vegetation.

Inséct-borne diseases are common in many parts of Belize. Malaria is endemic and is transmitted by several species of Anopheles mosquito including the

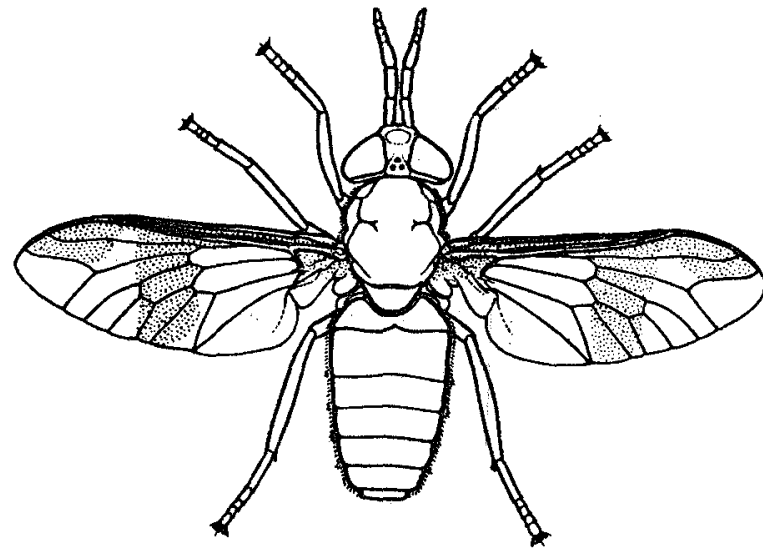

Fig. 5 Deer Fly, Chrysops 

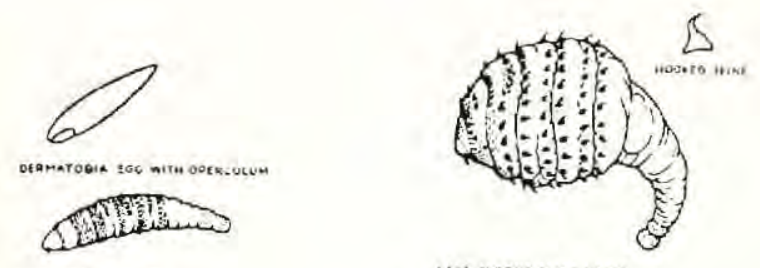

,jest siags LARYA

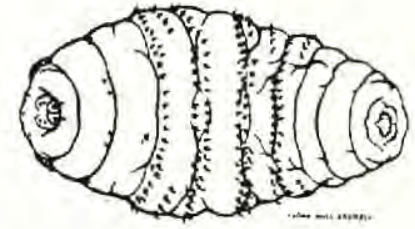

THIRO STAGE PREPUPAL LARVA

Fig. 6 Egg and larval stages of Dermatobia hominis (Reproduced from JRA MC 113 by kind permission of the Editor)

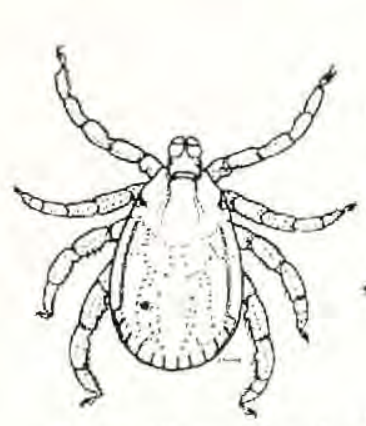

Dermacentor-unled male

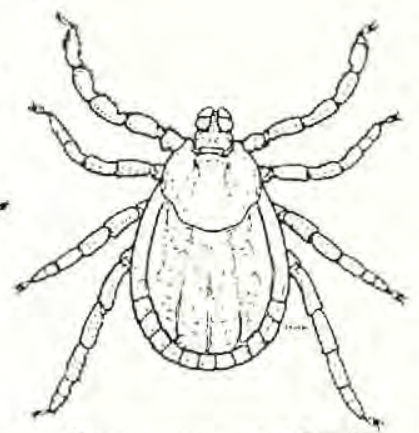

Dermacentor-unfed female
Fig. 7 Hard Ticks, Ixodidae

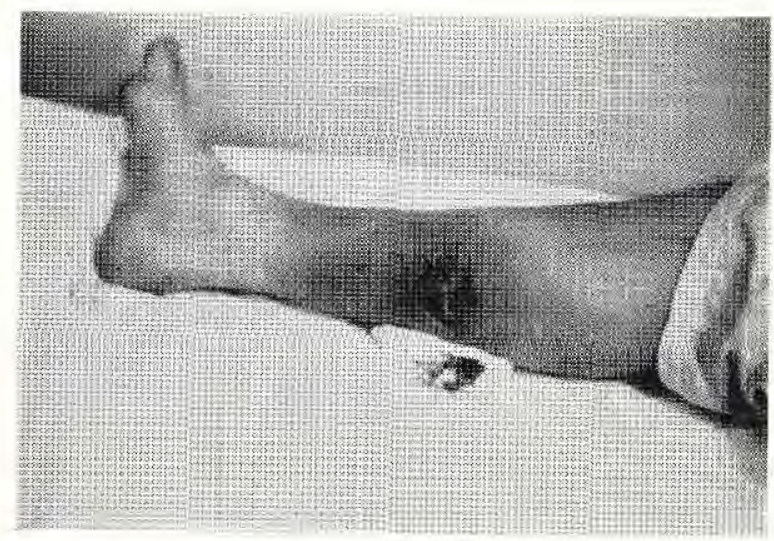

daytime biting Anopheles albimanus. Mosquitoborne viruses, particularly dengue fever, are common, 3 and a number of as yet unidentified arboviruses $\_$ occur, probably transmitted by both Anopheline and $\bigcirc$ Culicine mosquitoes and perhaps by other blood- कृ sucking flies as well as hard ticks. Filarial worms of dubious pathogenicity are transmitted by Culicoides, $\overrightarrow{\vec{F}}$ but onchoceriasis, carried by Simulium in many parts $\overrightarrow{0}$ of Central America, has not been reported from $\frac{C}{0}$ Belize. In the hot humid conditions of Belize, secondary infection of bites from all these arthropods is a frequent occurrence (Figs 8 and 9).

\section{Method and Results}

The incidence of insect bites among British Servicemen in Belize during November and December 1981 and January 1982 was investigated by abstracting those first attendances due to skin conditions from Army Forms W3181 (A) for Belize as a $\vec{\sim}$ whole, and AFs W3181 for the Station Hospital at co Airport Camp (Army and RAF personnel), and medical centres at Holdfast and Rideau Campe (Army, mainly British infantry personnel) and Salamanca Camp (Gurkha personnel). These figuress 옹 for skin infections were then investigated in treato․ $\vec{c}$ ment books and those due to insect bites were isc్फे ฏ lated. The results are shown in Tables 1,2 and 3 aकी टा incidence per 1000 personnel, the total number $\Phi^{2}$ Servicemen in Belize boing 1413 in November 198 1439 in December and 1418 in January 1982. Theso figures show that insect bites and the resulting secondary infection are the largest single specific cause of morbidity in Services personnel in Belize.

\section{Discussions and Conclusions}

People respond in different ways to the effects of insect bites, the variation depending upon the type of bite and the degree of immunity of the individual.

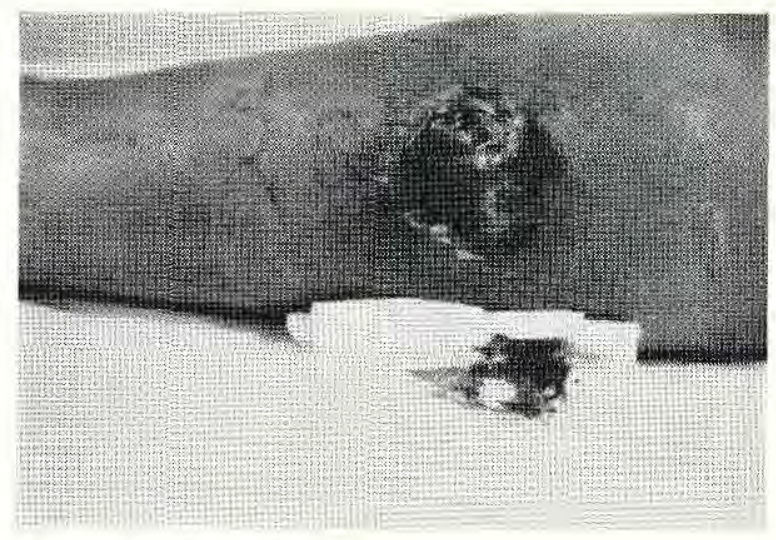

Figs. 8 \& 9 Secondarily infected mosquito bites in Belize 
Table 1

Monthly rate per 1,000 personnel for November 1981

\begin{tabular}{lccccc}
\hline & $\begin{array}{c}\text { Airport } \\
\text { Camp }\end{array}$ & Holdfast & Rideau & Salamanca & $\begin{array}{c}\text { Belize } \\
\text { Garrison }\end{array}$ \\
\hline Number reporting sick per 1000 in location & 240 & 450 & 970 & 220 & 430 \\
\hline Cause per 1000 reporting sick & & & & & \\
Insect bites & 116 & 110 & 202 & 0 & 145 \\
Other skin conditions & 169 & 110 & 156 & 75 & 144 \\
Respiratory & 84 & 36 & 32 & 570 & 93 \\
Alimentary & 84 & 51 & 140 & 25 & 98 \\
Injuries & 253 & 360 & 284 & 175 & 286 \\
Other causes & 294 & 334 & 188 & 155 & 234 \\
\hline
\end{tabular}

Table II

Monthly rate per 1,000 personnel for December 1981

\begin{tabular}{|c|c|c|c|c|c|}
\hline & $\underset{\text { Camp }}{\text { Airport }}$ & Holdfast & Rideau & Salamanca & $\underset{\text { Gelize }}{\text { Garrison }}$ \\
\hline Number reporting sick per 1000 in location & 600 & 450 & 820 & 260 & 410 \\
\hline \multicolumn{6}{|l|}{ Cause per 1000 reporting sick } \\
\hline Insect bites & 67 & 115 & 207 & 0 & 160 \\
\hline Other skin conditions & 307 & 274 & 195 & 102 & 198 \\
\hline Respiratory & 53 & 87 & 32 & 480 & 92 \\
\hline Alimentary & 94 & 40 & 109 & 146 & 84 \\
\hline Injuries & 241 & 255 & 280 & 170 & 240 \\
\hline Other causes & 238 & 229 & 177 & 102 & 226 \\
\hline
\end{tabular}

Table III

Monthly rate per 1,000 personnel for January 1982

\begin{tabular}{lccccc}
\hline & $\begin{array}{c}\text { Airport } \\
\text { Camp }\end{array}$ & Holdfast & Rideau & $\begin{array}{c}\text { Salamanca } \\
\text { 300 }\end{array}$ & $\begin{array}{c}\text { Belize } \\
\text { Garrison }\end{array}$ \\
\hline Number reporting sick per 1000 in location & 320 & 550 & 700 & & 450 \\
\hline Cause per 1000 reporting sick & & & & & \\
Insect bites & 79 & 334 & 281 & 0 & 205 \\
Other skin conditions & 242 & 155 & 117 & 200 & 175 \\
Respiratory & 103 & 107 & 33 & 254 & 95 \\
Alimentary & 49 & 11 & 135 & 72 & 69 \\
Injuries & 212 & 255 & 208 & 345 & 234 \\
Other causes & 311 & 136 & 223 & 127 & 220 \\
\hline
\end{tabular}

Having inserted its mouthparts to bite, an insect typically injects a small quantity of anticoagulant saliva to prevent the blood of its victim from clotting. This saliva has antigenic components and contains pharmacologically active substances such as histamines, haemolysins, hyaluronidase and toxic polypeptides. Some biting insects may also cause significant traumatic and chemical tissue damage. This together with antibody-antigen reactions, and the effects of proteolytic enzymes and irritants in- jected by the insect, stimulate the release of histamine and other tissue reaction mediators. This release may in turn cause local oedema, papules, vasodilation, vaso-permeability and smooth muscle contraction.

The immunology of insect bites is complex. Nonsensitised individuals bitten by insects will not respond, others may not respond because of tolerance, or may experience an immediate or delayed hypersensitivity reaction. The immediate reaction, a 
rapid antibody mediated response, can present as an extreme localised cutaneous reaction or rarely as generalised anaphylaxis. Delayed hypersensitivity is a cell mediated response occurring some 48 hours after the bite and typically presents as a papule with marked pruritis, considerable erythema, oedema and induration. Hypersensitivity, perhaps due to a genetic factor, varies greatly from person to person, and may be attributed to a specific allergy, imbalance or lack of pharmacological mediators.

\section{Analysis of Belize Results}

Results indicate that in the four locations in Belize nearly one in five personnel reporting sick do so because of insect bites, with as many as one in three in the month of January at Holdfast. At Rideau nearly a fifth of all personnel reported sick due to bites in each of the three months under investigation. It is interesting to note that at Salamanca, a camp occupied at that time by Gurkhas, not one soldier reported sick because of bites during the period, and but for this the total proportion for Belize as a whole would have been considerably greater.

Personnel reporting sick with bites were invariably affected on legs and feet which often rendered them unable to wear boots, thus decreasing their usefulness even more. From these results it is very apparent that insect bites are the cause of considerable loss of manpower and efficiency, and that every step should be taken to protect Services personnel from the attack of biting insects.

\section{Protective Measures}

Personal protection from bites is afforded by correct anti-mosquito drill (long sleeves and trousers, closed neck etc at dusk and during the hours of darkness )and the use of netted windows or mosquito nets at night. Insect repellent is effective if used regularly and if all exposed parts of the skin are treated. However the Army issue repellent (DET) is a strong $(75 \%)$ concentrate of the active ingredient diethyl toluomide in isopropyl alcohol, and stings if it comes into contact with mucous membranes. This is sometimes difficult to avoid in the climate of Belize where sweat runs into the eyes, nose and mouth, washing the repellent with it. Cream-based repellents are often more effective and more cosmetically acceptable, but apart from the combined sunscreen-insect repellent which is not easily available, these are not on issue. Servicemen invariably purchase proprietary brands of cream or aerosol insecticides from local stores, or simply prefer to be bitten, rather than use the crude Army issue repellent. Mosquito bed-nets impregnated with a $1 \%$ solution of permethrin deter sandflies and Culicoides from crawling through the mesh to bite.
It is often difficult, especially when asleep, to avoid scratching a bite, but if this can be pre- $Z$ vented for 5-10 minutes after attack the reaction $\mathbb{8}$ will often be minimal since the irritant saliva remains? very much more localised.

More general methods of pest control can be satisfactorily adopted to reduce the number of biting $\overrightarrow{\vec{\sigma}}$ flies. The most effective of these is the use of aspace-spray concentrate insecticide dispensed through a swingfog in the form of an aerosol mist which $\bar{\omega}$ has a knockdown and kill effect on any insect com- $\frac{\sigma}{\sigma}$ ing into contact with it. The fog should be appliedo during the flight period of the majority of biting कै flies, for example at dawn and dusk when sandflies, $\overrightarrow{0}$ midges and most mosquitoes will be affected.

These basic and readily available preventive mea- $\vec{\omega}$ sures, combined with active and efficient health education, will considerably alleviate the incidence of insect bites which in Belize are the cause of a? major and unnecessarily high morbidity among $\vec{N}$ Servicemen.

\section{Acknowledgements}

The authors acknowledge the kindness of Jol Hull Grundy, former Lecturer in Entomology at the Royal Army Medical College, for allowing the use of his drawings in this paper.

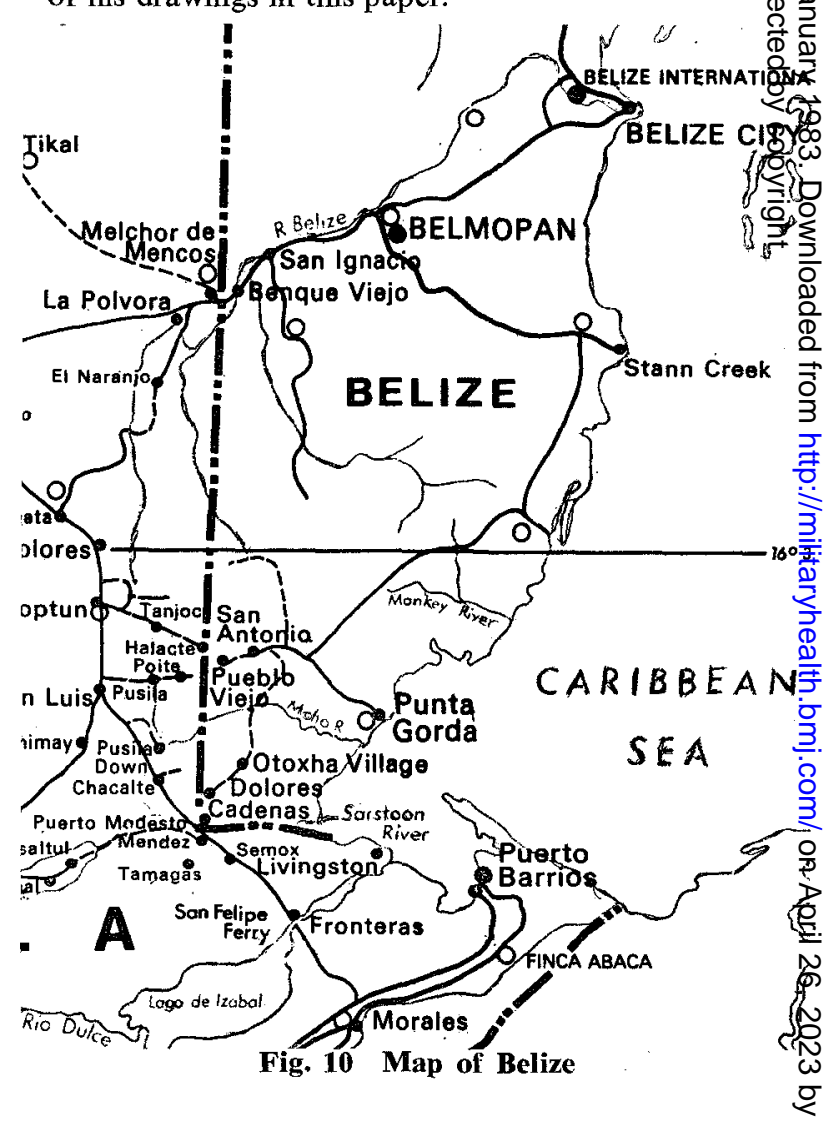

